\title{
DIE SONDEVAL SE RADIKALE INVLOED OP DIE REG
}

\author{
Dr. C. J. Smit.
}

\section{Inleiding}

Elkeen wat deur die reg geboei word, word die een of ander tyd aangespreek deur die vraag of die reg konsekwent as rég gepositiveer word, ook in 'n gelowige regsgemeenskap-selfs ook in die kerk as 'n regsgemeenskap. Word daar nie dikwels onreg in die naam van die reg gepleeg nie? En is byvoorbeeld die ongelowige wat God verloën en sy Woord verwerp hoegenaamd in staat om reg te bedryf? Antwoorde op hierdie vrae moet myns insiens gesoek word in 'n skriftuurlike beskouing op die verhouding tussen die reg en die sondeval. Dáár lê die sleutel.

\section{Voor die sondeval}

Voor die katastrofale gebeure in Genesis 3, toe die mens die leuen van Satan geglo het dat hy soos God sou word (en derhalwe oor die reg sou beskik), was daar geen uiterlike regsorde nodig nie. Dit beteken nie dat daar toe geen (ingeskape) wet was nie; dit beteken wel dat die formele wet en alle uiterlike regsreëls vir die ordening van 'n samelewing toe nie nodig was nie. Die regsorde wat toe geheers het, was 'n innerlike regsorde wat in die volkome harmonie tussen Skepper en skepsel bestaan het. ${ }^{1}$ ) Omdat daar volkome vrede geheers het, was daar volkome orde. ${ }^{2}$ ) Voor die sondeval was dié orde die beheersende kwaliteit van die hele werklikheid.

Die orde was volkome. Daar was geen onreg nie, slegs reg. Die volmaakte regsorde het bestaan in God se onverhinderde reg op sy skepping, én in die onbelemmerde regsband tussen God en die mens, maar ook in die ongeskonde reg wat die mens op die aarde ontvang het. God het aan die mens heerskappy gegee waarin die mens se reg ontplooi het. Daar was ook 'n ongeskonde regsverhouding tussen dic mense onderling. Daarvan is die huwelik, vooór die val, 'n sprekende voorbeeld. Ook dié regsbetrekking het geen formele regsreëls en bepalinge nodig gehad nie. Vanweë die ongeskondenheid van die verhouding waarin die vrou as hulp vir die man gestel is, was dit 'n innerlike, volkome harmonieuse regsbetrekking.

Aan die regsorde voor die sondeval moenie gedink word in terme van ons formele regsorde waardeur die kwaad bedwing moet word nie. Aan daardie regsorde moet gedink word in terme van God se ongeskrewe reg op die totaliteit van die mens en die mens se onbelemmerde ooreenstemming met God se wil.

Uit die reg wat reeds van voor die sondeval geld, kan gekonkludeer word dat die reg tot die skeppingsorde behoort. Die reg is deur God in die voor-sondevalse skepping ingeskape. Hoewel Satan se aanslag in die paradys juis op die reg van God gemik is, is die ingeskape reg nie vernietig nie: die reg het rég gebly. Die 'menslike reg', as die deur die mens gepositiveerde reg, het egter vanweë die verduistering deur die sonde terdeë in die slag gebly. Die onteenseglike gevolge van die sondeval op dié gebied hou onder meer in dat 
die mens òf nie die positiewe reg goed (op 'n juiste wyse) vorm nie - vanweë sy onvolmaaktheid en gebreke, of hy kan onreg in die gedaante van reg positiveer - eweneens vanweë sy onvolmaaktheid en gebreke. ${ }^{3}$ )

\section{Die Wet}

Onder die begrip 'wet' moet die middel verstaan word wat God reeds voor die sondeval (met die skepping) ingestel het om sy skepping te orden en in stand te hou. Vir die doel van 'n noodsaaklike onderskeid in die wetsleer bied die wysbegeerte van die wetsidee 'n bruikbare insig. Hiervolgens kan die wet in drieërlei verskyningsvorms onderskei word ${ }^{4}$ :

(i) Die religieuse wet: Hieronder moet God se wet(te) verstaan word, soos wat $\mathrm{Hy}$ dit in sy Woord gegee het en verbesonder het in die dekaloog wat weer in die liefdesgebod saamgevat is. Die religieuse wet beskou ek in onderskeid met God se kosmiese struktuurwet en God se modale wet as God se positiewe wet.

(ii) Die kosmiese struktuurwet: Hieronder moet die wet(te) verstaan word waardeur die vaste struktuur van God se skepping beheers word. "Elke geskape ding (stof, plant, dier en mens) het as individuele entiteit maar ook in ' $n$ groepsverband (die boom én die bos, die blom én die tuin, die skaap én die kudde, die enkele mens én die vereniging van mense) 'n onveranderlike struktuur ooreenkomstig die wet(te) wat God daarvoor gestel het. Ooreenkomstig die bedoelde struktuurwet(te) bly 'n dier altyd 'n dier en kan dit nooit 'n mens word nie, en is die staat 'n staat en nie kerk nie". 5 .

(iii) Die modale wet: Hieronder moet die wet(te) waarvolgens die dinge en strukture in die skepping fungeer, verstaan word. Die funksies van stof, plant, dier en mens (as indiwidue én in 'n groepsverband) word georden deur die modale wet(te). Kragtens die struktuurwet is 'n ding wat hy is, maar ooreenkomstig die modale wet fungeer die ding ooreenkomstig die aard van sy struktuur. Die modale wette wat God self gevorm en in die skepping gelê het om vir die funksies van die skepsele te geld, word natuurwette genoem. Daar is ook ander modale wette wat God slegs in beginsel voorsien het, met die opdrag aan die mens om dié bedoelde beginsels tot geldende (gepositiveerde) wette te vorm. Sulke wette word in hulle gepositiveerde vorm 'norme' genoem'. Hiervolgens bepaal 'n natuurwet wat is, en 'n norm bepaal wat behoort te wees. Natuurwette word nie deur die mens gemaak nie, hoewel hulle deur die mens ontdek moet word. Maar norme word deur die mens gevorm, uit bepaalde beginsels wat God neergelê het, kragtens sy opdrag aan die mens. Natuurwette geld vanself sonder die toedoen van die mens; norme geld alleen as dit deur die mens as geldende wet gevorm (gepositiveer) is. Sekere wette (die natuurwette) het God gegee, vir ander wette het Hy met die skepping slegs in beginsel voorsiening gemaak, en dit aan 
die mens opgedra om na die eis van sy plek en tydsituasie daardie beginsels tot geldende norme te positiveer (Gn $1: 28)^{7}$.

$\mathrm{Na}$ die sondeval en die gevolglike slawerny van die sonde, soos afgebeeld deur die Egiptiese slawehuis, sou die dekaloog (as God se positiewe wet) voortaan bekend maak wat die mens voor die sondeval suiwer met innerlike kennis verstaan het. Hierdie innerlike kennis het die mens kragtens sy innerlike beeltenis van God gehad, as gevolg waarvan die ongeskonde verhouding met God in volkome harmonie tot uitdrukking kon $\mathrm{kom}^{8}$.

Hieruit kan gekonkludeer word dat die formele wet (God se positiewe wet, en die mens se gepositiveerde wet(te) in soverre dit as norm met die godgegewe juridiese beginsels ooreenkom) die wetlike én wettige reëling van die reg na die sondeval is. Trouens, die formele wet het as gevolg van die sondeval noodsaaklik geword om die kwaad te bedwing.

\section{Na die sondeval}

Deur die sonde is die kennis van die reg verduister. En deur die sonde het ook die mens se wil in vyandskap teenoor God omgeslaan ${ }^{10}$. Die mens se verstand is ernstig gekortwiek, sy insigte tot eensydighede versplinter en sy wil gedegenereer tot vervormbare klei in die hande van Satan. Want die mens het sy verhouding met sy Maker vernietig; die kind het sy naelstring deurgekap.

Die gevolge van die sondeval is onjuiste orde en wanorde in die mens se beste pogings tot ordening, skynreg en onreg in die mens se deurtastendste poging om reg te vorm. Die feit dat daar egter tog in 'n mate reg in die mens se regsvorming te vind is, en orde in die mens se ordening, is te danke aan die "klein oorblyfsels" 12 van die paradystoestand (én van die beeltenis van God) wat nog in hom oorgebly het ${ }^{13}$.

Dit beteken dat alhoewel die mens sy innerlike regskennis verloor het, het hy nie sy innerlike regsbesef verloor nie ${ }^{14}$.

Die oorspronklike geregtigheid en moraal het met die sondeval verdwyn: "... non tamen ita in universum in homnibus extinctus fuit aut mentis vigor aut virtutis sensus, quin scintillae quaedam principiorum justi \& honesti superfuerint, quafi rudera egregiae domus, aut tabulae ex naufragio subductae; atque adeo cordibus insculptae divinitus \& innatae remanserint nonnullae justitiae \& aequitatis regulae, quid licítum illicitum re, quae agenda, quae fugienda sint ..." 15 .

Calvyn sê in sy kommentaar op Romeine $2: 14$ dat "... nonnullam se habere iustitia regulam... Habent ergo legem sine lege: quia utcunque scriptam Mosis legem non habeant, notitia tamen recti et aequi nequaquam prorsus carent" ${ }^{16}$. En in sy kommentaar op Romeine 2:15 druk Calvyn hom so uit: "Praeterea nec ex eo colligendum est, hominibus inesse plenam legis cognitionem, sed quaedam duntaxat iustitiae semina esse indita ipsorum ingenio..."1". Dieselfde gedagte verwerk hy in sy Institusie ${ }^{18}$ waar hy hy leer dat daar van nature 'n Godsbesef in die mens se hart ingegrif is, maar dat 'n mens nie van nature tot Godskennis kan kom nie vanweë die 
verduistering deur die sonde. Juis vanweë dié verderf, interpreteer die mens sy Godsbesef van nature verkeerd, dit lei dan tot afgodsdiens en valse godsdienste ${ }^{19}$.

Die konklusie kan gemaak word dat vanweë die oorblywende regsbesef in die deur die sonde verwronge mens, ook die ongelowige mensheid terdeë bewus is van die grondliggende betekenis van die reg, waarsonder die (ordelike) voortbestaan van die mens onmoontlik sou wees. Vir die heiden is dit wel moontlik om 'van nature' 'n mate van reg, ooreenkomstig die wet, te bedryf omdat "die wet in hulle hart geskrywe staan"20. Ook die ongelowige kan dus vanweë sy regsbesef juridiese beginsels (wat deur God ingeskape is) tot geldende norme (waarin God se reg weerspieël word) positiveer. Maar die ongelowige kan ook vanweë sy regsbesef op grond van Godgegewe natuurwette, geldende norme positiveer wat ondanks die sondeval aan die betekenis van die woord reg voldoen.

Die volgende voorbeelde kan ter illustrasie van bogenoemde ge. dagtegang voorgehou word: Ook 'n ongelowige owerheid sou vanweë sy regsbesef 'n juridiese beginsel daarin herken dat alle kinders onder dieselfde staatsregtelike bestel gelyke geleenthede vir skoolonderwys moet kry. Uit die juridiese beginsel sal hy 'n aantal geldende norme (as 'ordinansies' en 'wette') positiveer waardeur die toelating tot skole, die inrigting van skole, die opleiding van onderwysers, ensovoort gereël word. Eweso sou 'n ongelowige owerheid vanweë sy regsbesef ook die natuurwet daarin herken dat daar tekorte aan lewensnoodsaaklike voedselsoorte sou ontstaan indien alle boere in dieselfde seisoen byvoorbeeld slegs pampoene sou plant. Op grond van hierdie natuurwet sal die owerheid 'n aantal geldende norme positiveer waarvolgens voedselverbouing beheer word.

Die ander kant van die munt is egter dat die ongelowige (maar ook die gelowige) ${ }^{21}$ norme kan positiveer wat geheel en al strydig met die liefdesgebod in God se Woord is. Sulke norme stry teen God se gepositiveerde wet. In die naam van die reg voer onreg dan 'n skrikbewind. Die 'reg' wat sy oorsprong en sy regsnorm in die mens het, kan maklik tot sulke skynreg ontaard. Die gelowiges sal egter, omdat hulle God se positiewe wet as 'n reël vir hulle dankbaarheidslewe onderhou, die genade ontvang om tussen reg en skynreg te kan onderskei"2z. Waar die wêreld se regstrukture vrede op aarde belowe, op grond van die mensgebonde (humanistiese) reg waarin alle geloofsrigtings 'n grootste gemene deler vind, word dikwels onreg met die skyn van reg gepositiveer. Die hoofdoel is die eenheid van 'n wêreldbroederskap, waaraan kerke ook vrymoedig (om nie 'uitbundig' te sê nie) dwarsoor die wêreld meedoen. Behep met die idee van 'menseregte' en 'demokratisering' handhaaf die mens homself as 'regsbepaler'. Sedert die paradysleuen speel hy steeds in die hand van Satan. So word die wêreld reeds voorberei vir die tyd waarin die ou slang wat die duiwel en die Satan is losgelaat word om die nasies te verlei ${ }^{23}$. In die begin het die geskiedenis van verleiding in die paradys plaasgevind, en die mens, wat geswig het, is na die woestyn toe uitgedryf. Aan die einde van die geskiedenis sal die verleiding in dié woestynbedeling plaasvind, en die mens wat 
staande bly sal die paradys ingelei word. Satan se loslating word reeds daarin voorberei dat die onreg onder die voorwendsel van die reg selfs die kerk ingedra word deur die valse profeet, selfs met die hulp van (tydelik) verblinde ware kinders van God: "So sal die wedloop om die reg (soos die wêreld dit sien: uit die mens en tot die mens) uítloop op die verskriklike chaos van die eindtye. Die mens glo die leuen al hoe meer. God het hulle oorgegee om dit te glo omdat hulle ' $n$ behae in die ongeregtigheid het (vgl. 2 Ts $2: 8 \mathrm{vv}$ )."

Slegs in soverre ons ons reg - en ons kerkreg - in die lig van God se geopenbaarde regshandelinge met die mens beoefen, kan ons in óns regshandelinge op die waarheid aanspraak makk. Uiteindelik kom Jesus Christus weer, dán as regter, om in die eindoor deel die mens se reg in die lig van God se reg te beoordeel. Dan word God se reg finaal herstel. Dit is die hóóp van elkeen wat nou reeds in Christus leef in die verwagting van nuwe hemele en 'n nuwe aarde wat God belowe het en waarin zeregtigheid sal heers. 25 .

\section{Samevatting}

Voor die sondeval was daar geen uiterlike regsorde nodig nic. Die reg het as 'n innerlike volkome harmonieuse orde gegeld. Daar was volkome vrede tussen God en mens en tussen mens en mens. Die reg was ' $n$ onbelemmerde handhawing van God se wil. Hieruit blyk dat die reg 'n skeppingsgegewe is.

Die wet wat deur God gegee is, hoort eweseer tot die skeppingsorde. Voor die sondeval het die wet nie-geskrewe, nie-formeel op 'n innerlike ingeskape wyse gegeld. Tó nie om die kwaad to bedwing nie, maar om die harmonie te vergestalt. Die wet moet in drieërlei verskyningsvorms onderskei word:

(i) Die religieuse wet, oftewel God se positiewe wet, soos wat dit in die dekaloog verbesonder en in die liefdesgebod saamgevat is.

(ii) Die kosmiese struktuurwet waardeur die vaste struktuur van God se skepping beheers word.

(iii) Die modale wet waardeur die funksies van stof, plant, dier, mens (as individue en in 'n groepsverband) georden word. Die modale wette word onderskei in natuurwette en beginsels. Laasgenoemde word deur die mens tot norme gepositiveer. 'n Natuurwet bepaal wat is en 'n norm bepaal wat behoort te wees. Natuurwette geld vanself, norme geld slegs as dit deur die mens tot geldende wette gepositiveer word.

$\mathrm{Na}$ die sondeval is die mens se kennis van die reg verduister, maar sy besef van die reg het hy nie verloor nie. Vanweë die verduistering deur die sonde interpreteer die mens sy Godsbesef van nature verkeerd, dit lei dan tot afgodediens en valse godsdienste. Maar vanweë die mens se regsbesef is dit ook vir 'n ongelowige moontlik om juridiese beginsels in die modale wet te herken en tot norme te positiveer (waarin God se 'ingeskape' reg dus weerspieël word). Die anderkant van die munt is dat die mensheid wat die reg 
in die mens soek en homself die bepaler van die reg ag, onreg in die naam van reg kan positiveer en afdwing.

Wie derhalwe nie gelowig met die sondeval rekening hou en God se regshandelinge met die mens (as die geopenbaarde Waarheid in sy Woord) in sy eie regshandelinge vertolk nie, sal sy regsbeskouing op ' $n$ idealistiese mensbeeld grond en so in regspositiwisme versink waarin die mens die maatstaf van sy regshandelinge word. Só word die 'mediaanmens' die maatstaf waarvolgens literêre sensuur toegepas word; die meerderheid 'ampsdraers' op 'n sinode word die bepaler van die reg vir die kerk; en die ideaal van selfhandhawing (lees ook: 'groepsverheffing' of 'volksidentiteit') as die hoogste burgerlike strewe word die staatsregtelike norm waarvolgens bepaal word (hoe) om oor ander volke binne dieselfde staatsregtelike bestel te beskik. Wie dus nie eerlik en deurtastend met God se regshandelinge in sy Woord as regsnorm bemoeienis maak nie, vind die reg én die norm vir die reg in die mens self en stel die waarheid sodoende ondergeskik aan menslike voorkeur. Ter wille van die waarheid in die reg is dit derhalwe van primêre belang om God se regshandelinge met die mens in sy Woord ernstig op te neem en dit deurtastend na te vors as die normatiewe basis waarop ' $n$ verantwoorde regsbeskouing en 'n toereikende regsbestel geskik moet word: "Hy het jou bekend gemaak, o mens, wat goed is; en wat vra die Here van jou anders as om reg te doen en liefde te betrag en ootmoedig te wandel met jou God?" (Miga 6:8).

\section{AANTEKENINGE}

1. Vgl. Fabius. D. P. D., Zonde en recht, 1895 , p. 16.

2. Die verhouding tussen vrede en orde het ek uiteengesit in Kerkreg en kerkorde in die lig van God se reg en orde vir sy kerk, 1985, ongepubliseerde proefskrif, p. $213 \mathrm{v}$.

3. Hieroor het Stoker, H. G. insiggewend geskryf, vgl. Oorsprong en rigting, dl. $2,1967, p .113 v$ en Die aard ien rol van dle reg: 'n wysgerige besinning, RAU, A36, 1970, p. 9v.

4. Van Zyl, F. J. \& Van der Vywer, J. D., Inleiding tot die regswetenskap, 2de uitg., 1982, p. $18 v v$.

5. Idem, p. 19.

6. Idem, p. 20.

7. Idem, p. 37v.

8. Vgl. H. K. Son. 3, vr. 6. 
9. Vgl. Fabius, D. P. D., ibid, p. 34v.

10. Idem, p. 38v.

11. Vgl. Rm. $1: 21 ; 3.9-20$

12. N.G.B., art. 14.

13. D.L.R. III en IV, 4.

14. Vgl. Rm 1:18-21; $2: 14 \mathrm{v}$; Calvyn, OC $49: 22-25,37 \mathrm{v} ;$ Bouwman. H, Gereformeerde Kerkrecht, dl. I, 1970, p. 8; Polman, A. D. R., Onze Nederlandsche Geloofsbelijdenis: verklaard uit het verleden geconfronteerd met de heden, dl. 34, s.j., p. 103-106 (oor N.G.B., art 14).

15. Voet, J., Commentarius ad Pandectas, I, i, 1, 1707:

"... en tog is die krag van verstand of die gevoel van deug nie so volkome in die mensdom uitgewis dat daar nie enkele vonkies van die beginsels van wat reg en eerbaar is in hulle oorgebly het nie. Dit is soos afval van 'n pragtige huis of soos planke wat opdrifsels van 'n skipbreuk is. Sekere reëls van geregtigheid en billikheid het so in die mens se hart ingegraveer en daarin geborge gebly dat dit aan elkeen voorsê wat wettig (geoorloof") en wat onwettig (ongeoorloof) is, wat hy mag doen en wat hy moet ontwyk...".

16. OC $49: 37 v$ : “. . dat hulle in 'n mate (nie niks nie) die reël van geregtigheid het... So het hulle dan 'n wet, want hoewel hulle nie die geskrewe wet van Moses het nie, is hulle nogtans nie geheel en al sonder kennis van wat goed en reg is nie."

17. OC 49:38: "Buitendien moet 'n mens nie daaruit verstaan dat in die mense 'n volkome kenn's van die wet is nie, maar dat slegs ('n bietjie) saad van die geregtigheid in hulle aard afgedruk is." Vgl. hierby D.L.R. III en IV, 4: "Daar het wel ná die val in die mens nog enkele straaltjies van die lig van die natuur oorgebly waardeur hy enige kennis behou van God, van die natuurlike dinge, van die onderskeid tursen wat betaamlik en onbetaamlik is, terwyl hy ook enigsins 'n strewe openbaar na deug en uiterlike tug."

18. I, iv, 4 .

19. Rm $1: 21-23$; vgl. ook weer OC $49: 38$.

20. Rm. 2 : 15; Bouwman, H., ibid, p. 8; Fabius, D. P. D., Mozaisch en Romeinsch recht, 1890, p. $6 \mathrm{v}$.

21. Rm. $3: 10$.

22. Mt. $24: 24$.

23. Vgl. Op $20: 7-10$ in konteks met Mt. $24: 22$.

24. Van der Linde, G. P. L., Kerkreg, dl. I, ongepubliseerde klasdiktaat, 1980/ 81, p. 25.

25. 2 Pt. $3: 13$. 